\title{
SINERGIAS Y CONFLICTOS ENTRE DESARROLLOTURÍSTICOYOTROS SECTORES ECONOMICOS. EL CASO DEL TURISMO DE INTERESES ESPECIALES EN LA REGIÓN DE LOS RÍOS
}

\author{
Guillermo Pacheco Habert \\ Universidad Austral de Chile \\ guillermopachecohabert@gmail.com \\ Pablo Szmulewicz Espinoza \\ Universidad Austral de Chile \\ pablo.szmulewicz@gmail.com
}

\section{RESUMEN}

El turismo de intereses especiales (TIE) se relaciona directamente con el uso del patrimonio natural y cultural de los territorios en donde se desarrolla. El TIE que incluye al turismo aventura, ecoturismo, turismo cultural, turismo indígena, turismo rural y agroturismo, se dirige hacia una demanda selectiva y usa el patrimonio natural y cultural en la experiencia turística, por ejemplo: ríos, lagos, mar, bosques, ruinas, etc. El desarrollo turístico se ve directamente influenciado por las relaciones y conflictos que se presentan con otros sectores productivos. En muchas ocasiones, el turismo tiene un alto grado de compatibilidad con otros sectores productivos, por ejemplo el agroturismo con el sector agropecuario, el turismo cultural con la pesca artesanal, etc. Sin embargo, también se presentan conflictos e incompatibilidades, que es de mucha importancia identificar, debido a los efectos que se aprecian principalmente en el mediano y largo plazo. Respecto al caso específico del TIE en la Región de Los Ríos se identifican diversos conflictos productivos, cuyos efectos particulares no han sido dimensionados ni estudiados por la ciencia, sin embargo diversos estudios internacionales revelan los efectos negativos de muchas practicas productivas que se llevan a cabo en la región y no se regulan eficientemente. Por otra parte, encontramos sinergias especialmente en la ruralidad aquí el turismo pasa a ser una herramienta productiva alternativa, en estos casos el complemento con la actividad agropecuaria, forestal y pesquera a pequeña escala, con alta participación familiar, son grandes potencialidades que permiten disminuir conflictos y fomentar las sinergias a través del desarrollo de buenas prácticas productivas en localidades y regiones.

Palabras claves: Desarrollo, Turismo de Intereses Especiales, Sinergias Productivas, Conflictos Productivos. 


\title{
SYNERGIES AND CONFLICTS BETWEEN TURISTIC DEVELOPMENT AND OTHER ECONOMIC SECTORS. THE CASE OF SPECIAL INTEREST TOURISM IN REGION DE LOS RÍOS, CHILE.
}

\author{
Guillermo Pacheco Habert \\ Universidad Austral de Chile \\ guillermopachecohabert@gmail.com \\ Pablo Szmulewicz Espinoza \\ Universidad Austral de Chile \\ pablo.szmulewicz@gmail.com
}

\begin{abstract}
Special Interest Tourism is related to the use of nature and cultural resources directly. This kind of tourism - which includes adventure tourism, ecotourism, rural tourism, cultural tourism, agrotourism - is focused on a selective demand and based on a wide range of natural and cultural resources (i.e. rivers, lakes, woodlands, ruins).

Because of this variety of resources, tourism development is influenced by relationships and conflicts with other productive sectors (livestock, agriculture, industrial fishing, handcraft fishing, energy production, and forest industry). In many cases, tourism is highly compatibility with these sectors; however, conflicts and incompatibilities arise present too. As a result, identifying the risk factors affecting sustainable tourism, as well as the relations between tourism with other productive sectors becomes critical.
\end{abstract}

A case study approach is adopted to investigate these relationships regarding Special Interest Tourism in Region de Los Ríos (Chile). In the case, a wide variety of productive and territorial conflicts are identified. Several research shows negative impacts on tourism development triggered by many other productive sectors in the region, specifically because of the lack of regulation. In turn, synergies between tourism and other sectors are also identified. In this last case, tourism has become an alternative tool and complementary strategy for local development, contributing to reduce conflicts for the use of land and promoting the adoption of best practices in local communities.

Key words: special interest tourism, regional development, productive synergies, productive conflicts. 


\section{1.- PRESENTACION.}

El turismo de intereses especiales (TIE.) se relaciona directamente con el uso del patrimonio natural y cultural. El TIE considera al turismo aventura, ecoturismo, turismo cultural, turismo indígena, turismo rural y agroturismo, se dirige hacia una demanda selectiva, usando gran variedad de naturaleza en la experiencia turística, por ejemplo: ríos, lagos, mar, bosques, etc.

El desarrollo turístico se ve directamente influenciado por las relaciones y conflictos que se presentan con otros sectores productivos. En muchas ocasiones, el turismo tiene un alto grado de compatibilidad con sectores productivos, por ejemplo el agroturismo con el sector agropecuario, el turismo cultural con la pesca artesanal, etc. Las sinergias entre turismo y otros sectores productivos, se producen cuando existe un cierto grado de desarrollo sostenible, en donde ambas actividades productivas se complementan y pueden coexistir, sin problemas sociales, ni ambientales involucrados que perjudiquen a una actividad productiva en especifico. Según Ceballos Lascuraín (1998) la actividad turística sustentable es aquella modalidad turística ambientalmente responsable, consistente en viajar o visitar áreas naturales relativamente sin disturbar, con el fin de disfrutar, apreciar y estudiar los atractivos naturales (paisaje, flora y fauna silvestre) de dichas áreas, así como cualquier manifestación cultural (del presente y del pasado) que pueda encontrarse allí a través de un proceso que promueva la conservación, tenga bajo impacto ambiental y cultural y propicie un involucramiento activo y socioeconómicamente benéfico de las poblaciones locales.

En relación a lo anterior la actividad turística sustentable necesita desarrollarse en lugares con bajo impacto ambiental, donde se promueva la conservación y los beneficios para los residentes locales. En este caso es imposible que exista turismo sustentable si existen conflictos productivos con efectos sociales y ambientales a largo plazo. Debido a esto, el turismo de intereses especiales, es un pilar para el desarrollo sostenible de muchas localidades y regiones de Chile. Las sinergias productivas entre turismo y otros sectores, se desarrollan en muchos casos de forma espontánea en la ruralidad. Es por eso que el turismo rural es el principal escenario en la identificación de sinergias productivas.

En nuestro país la mayoría del turismo se desarrolla en áreas rurales, por lo que los residentes de estas áreas han visto como oportunidades económicas diversificar sus actividades y trabajar el turismo. Los casos más representativos se refieren al agroturismo, debido a que el sector agropecuario en las zonas rurales es uno de los pilares de producción local, por lo que el turismo ha tenido que complementarse con estas actividades tradicionales. Sin embargo , las sinergias entre turismo y otros sectores productivos, van más allá de lo que nos ofrece solamente el agroturismo, sino también en interacciones con la actividad forestal, pesquera y de generación energética. 
El ecoturismo, turismo aventura, turismo termal, agroturismo, turismo indígena etc. presentan sinergias con actividades productivas como la pesca artesanal, la conservación forestal y la generación energética. Sin embargo, estas sinergias en el caso nacional, con excepción del agroturismo, son más potenciales que reales debido a que cuesta encontrar experiencias determinadas con un desarrollo prolongado, pero si existen experiencias. Por ejemplo, la experiencia de turismo comunitario "Ecoturismo Puñihuil" en una caleta pesquera de Chiloé en la comuna de Ancud. Y la red de parques Mapu Lahual en la Provincia de Osorno, Región de Los Lagos. Aunque existen estas experiencias, a nivel país, todavía son muy pocas, y se hace preeminente el fomento de las sinergias productivas en todas las regiones.

Sin embargo, también se presentan conflictos e incompatibilidades, que es de mucha importancia identificar, debido a sus efectos que se aprecian principalmente en el mediano y largo plazo. Entendemos como conflictos productivos, de un sector económico con otro, a la coexistencia de acciones productivas con tendencias contrarias y perjudiciales entre estas. Sin embargo, cabe mencionar que en la actualidad se visualizan como conflictos, pero en el mediano y largo plazo muy posiblemente pueden ser incompatibilidades. Las incompatibilidades productivas se refieren a influencias altamente perjudiciales de un sector productivo hacia otro, siendo muy poco probable la coexistencia de ambos sectores. En este escenario los niveles de impacto ambiental y social son de carácter irreversible o de extremo deterioro.

Es necesario destacar que en la actualidad nos encontramos con diversos grados de conflictos, que lógicamente pueden ser superados, dependiendo de la magnitud que escale el conflicto y por supuesto dependiendo de los sectores en confrontación. Por lo tanto, es imperativo identificar los factores de riesgo que presenta un desarrollo sustentable del turismo, y las relaciones con otras actividades productivas: ganadería, agricultura, pesca industrial y artesanal, la producción energética y la industria forestal; que en definitiva impactan a los recursos naturales y turísticos en los que se basa el turismo de intereses especiales. Sin duda, los efectos negativos, a largo plazo, son mayores de los que podemos apreciar de inmediato.

En este artículo se analiza el tema de los conflictos productivos para los principales sectores económicos de la Región de Los Ríos en relación al turismo de intereses especiales, tema que últimamente se encuentra en boga en muchos territorios del país, pero que sin embargo los marcos legales no han permitido una planificación territorial integral. Gran parte de los municipios del país se auto consideran como turísticos, sin embargo, su propia planificación territorial y los pocos instrumentos legales de normalización y regulación no han permitido hasta la actualidad un desarrollo planificado. Sin embargo, ante un marco legal muy débil, algunos municipios realizan esfuerzos en la materia, tales como los Planes de Desarrollo Turístico, algunas ordenanzas, puesta en 
valor del territorio, fomento de la actividad, promoción de inversiones, información y promoción turística etc. De todas formas, estos esfuerzos aún siguen siendo insuficientes como para garantizar el desarrollo compatible de diferentes sectores productivos que compiten por el uso del territorio. El ordenamientos territorial principalmente en territorios rurales, es todavía insuficiente para las contingencias productivas y el turismo de intereses especiales, muchas veces estos son instrumentos indicativos, que no regulan ni normalizan un desarrollo estratégico del uso de los recursos. Asimismo, acontece con los instrumentos de ordenamiento territorial disponibles para el turismo, como lo son las Zonas de Interés Turístico (ZOIT). Un ejemplo ilustrativo de esto es lo que ocurre con el proyecto Hidroaysén en la Patagonia, en el sector de Lago Gral. Carrera. En ese sector, hay un proyecto para construir 5 centrales hidroeléctricas en los ríos Baker y Pascua.

En ese entorno paisajístico que ha sido definido muy cercanamente, las centrales comienzan donde comienza el río Baker, donde desagua el lago Gral. Carrera y el lago Bertrand. Ahí comienzan las 5 centrales. Sin embargo, toda la parte superior de las cuencas de los lagos, están definidas como Zonas de Interés Turístico, careciendo completamente de aplicación práctica. Proyecto que, comparado con la producción hidroeléctrica de otras centrales similares, duplica en generación energética a la central más grande que existe en este momento, la central Ralco. Y supera a Itaipú y supera a Cachías, supera a Colbún y supera a muchas otras centrales.

Por otra parte, las gobernanzas locales del territorio están subordinadas a los intereses políticos de las estructuras de los gobiernos, que generalmente no se encuentran acordes con los imaginarios de los residentes. En la mayoría de los proyectos o actividades productivas donde existen incompatibilidades o conflictos, no se ha considerado la participación ni la validación social, quedando supeditada a los intereses económicos globales o nacionales. En este contexto, actualmente se pueden describir los problemas territoriales en el uso de los recursos, que son atingentes al desarrollo del turismo de intereses especiales, sin embargo, es mucho más complejo visualizar estructuras de gobernanzas e instrumentos legales que normalicen los procesos de desarrollo de las sociedades regionales, sin depender de las voluntades político administrativas y de los grupos económicos.

\section{2.- OBJETIVOS Y METODOLOGÍA.}

\section{1.- Objetivos.}

a) Establecer los principales recursos naturales por cuyo uso compiten distintos subsectores y TIE en la región de Los Ríos.

b) Identificar los principales usos de los recursos y los aspectos de encuentro donde compiten distintos sectores productivos y el TIE. 
c) Establecer las posibles sinergias actuales y potenciales de otros sectores productivos y el TIE.

d) Analizar los conflictos de los principales sectores y el TIE.

\section{2.- Metodología.}

Este estudio corresponde a una investigación exploratoria, dado su carácter innovador en cuanto a la investigación turística por ser un tema muy poco abordado desde un enfoque complejo, el que incurre a dar cuenta sobre las interacciones de diferentes sectores productivos sobre el territorio, a través de argumentaciones científicas multidisciplinarias evidenciadas. Por otra parte, también se trata de una investigación descriptiva ya que otorga ciertos elementos que dimensionan sinergias productivas, como también conflictos que en algunos casos escalan a incompatibilidades. La temporalidad de este estudio es diacrónica, debido a la perspectiva de los datos expresados como causas de efectos en la sostenibilidad futura de los territorios de la Región de Los Ríos. Las fuentes de información utilizadas corresponde a fuentes secundarias (principalmente artículos científicos) y fuentes primarias, resultantes de talleres y jornadas participativas, en marco al proyecto: Agenda de Innovación Turística para la Región de Los Ríos 2009, ejecutado por el Instituto de Turismo de la Universidad Austral de Chile. A continuación se muestran los pasos metodológicos fundamentales efectuados en esta investigación.

a) Revisión de antecedentes existentes de los impactos y las relaciones de otras actividades productivas y el TIE.

b) Evaluación de los impactos y las relaciones de las actividades productivas y el TIE en la región de Los Ríos. Fueron identificados a través de talleres y jornadas participativas. Se mencionan a continuación:

- Primera Jornada Regional de Evaluación Turística, realizada el 1 de Abril en el Sanatorio Santa Elisa, en la comuna de San José de la Mariquina.

- Taller de Análisis de los Proyectos Estratégicos de la Agenda de Innovación Turística, realizado el 3 de Septiembre de 2009, en el Liceo People Help People de la comuna de Panguipulli.

- Taller de Validación de los Proyectos Estratégicos de la Agenda de Innovación Turística de la región de Los Ríos, realizada el 28 de Julio de 2009, en el Club de Leones de la comuna de Río Bueno.

En las mesas de trabajo de estos talleres, y en sus respectivas conclusiones desarrolladas en conjunto con actores del sector público, privado y académico, se 
estableció la preocupación por la interacción de otros sectores productivos con los recursos naturales primordiales para el TIE. Por lo que se identificaron algunos conflictos con otras actividades productivas.

c) Análisis prospectivo de relaciones y conflictos entre los principales sectores productivos regionales y el desarrollo del turismo de intereses especiales.

\section{3.- CONFLICTOS ENTRE DESARROLLO DEL SECTOR TURISMO Y OTROS SECTORES PRODUCTIVOS.}

\section{1.- Desarrollo del sector Turismo y el sector Agropecuario.}

La región de Los Ríos es una región ganadera, principal productora de leche y carne del país. La ganadería regional se basa primordialmente en ganado bovino y ovino, siendo el primero el más importante. Río Bueno es la comuna que registra la mayor cantidad de animales bovinos de la región y el país.

La actividad agropecuaria genera impactos ambientales, tanto a causa de los fertilizantes, plaguicidas, alimentación de animales, como por los efluentes, purines y emisión de patógenos de las actividades productivas de la masa ganadera. La contaminación ambiental se produce a través del aire y el agua, por lo que los recursos hídricos de la región, se ven afectados por la contaminación de aguas superficiales y subterráneas. La contaminación difusa ${ }^{1}$, es la principal razón de la contaminación indirecta de las aguas por absorción de nutrientes de N y P por parte de las praderas (lixiviación), como también el arrastre, generando la eutrofización de las aguas, por tanto la pérdida de biodiversidad en los ecosistemas acuáticos.

Según Alfaro et al. 2005, en estudios preliminares realizados entre 19981999 indican que se está generando una acumulación de estos nutrientes propios de los sistemas ganaderos. La eficiencia de uso promedio de $\mathrm{N}$ y $\mathrm{P}$ se incrementa en predios en que los potreros destinados a conservación de forraje se complementaba la fertilización inorgánica con orgánica (aplicación de purines y efluentes de lechería), reduciendo los montos de fertilizantes inorgánicos incorporados al predio. Sin embargo, la falta de capacidad de almacenaje de purines y efluentes de lechería, es causa del uso inadecuado de los fertilizantes en invierno, que influenciado por la alta pluviosidad favorece la pérdida de nutrientes. Actualmente en Europa, las investigaciones se dirigen hacia aumentar la eficiencia de uso de nutrientes en los sistemas ganaderos, para reducir la contaminación. Con la finalidad de proteger la calidad del agua, se han establecido regulaciones para minimizar la utilización de fertilizantes nitrogenados en sistemas agropecuarios

$\overline{1 \text { La contaminación }}$ difusa se refiere a una contaminación por vías indirectas, difíciles de controlar y regular, sin embargo las repercusiones y amenazas ambientales son inminentes por lo que se han reconocido a nivel mundial. 
intensivos, identificando Zonas Vulnerables al Nitrato (E. C. 1991).

Según Salazar (2005) en el documento "Impacto Ambiental de Sistemas Pecuarios" de INIA-Remehue, los efluentes de la actividad agropecuaria presentan altos valores de DBO (Demanda Bioquímica de Oxigeno) superiores a los generados por las aguas servidas en ciudades. Estudios realizados en la región de Los Lagos, indican valores de DBO que concuerdan con los citados en la literatura. Algunos estudios indican que el efluente producido por un silo de 500 toneladas de forraje cosechado en verde, es igual a las aguas servidas producidas en un día por una ciudad de 200.000 habitantes.

\section{2.- Desarrollo del sector Turismo y el sector Forestal.}

Según el Catastro del Uso del Suelo y Vegetación de la Región de los Ríos desde el año 1998 hasta 2006 los Bosques nativos han descendido en 15.637,3 há, mientras que las plantaciones han aumentado en 63.459.9 há. La principal razón de la disminución del bosque nativo fue el crecimiento de las plantaciones forestales, 20.121,6 há fueron convertidas en plantaciones. Las plantaciones forestales se nutren en su mayoría de especies exóticas como Pino Insigne y Eucalipto, las que han contribuido a la disminución del bosque nativo (Selva Valdiviana), generando la disminución de los recursos hídricos, impactos negativos a la diversidad biológica, y la belleza paisajística en relación a la tala rasa de plantaciones que desertifican el escenario natural y turístico.

La Selva Valdiviana es un recurso natural de importancia internacional, es un tipo de bosque templado lluvioso presente desde la Región del Maule hasta la Región de Aysén en Chile y las zonas vecinas de la República de Argentina. A este territorio comprendido se le denomina la "Eco región Valdiviana", que contiene los bosques templados lluviosos mas australes del mundo (WWF Chile 2009).

Según lo anterior, la disminución del bosque nativo, o de la Selva Valdiviana, es una perdida ecológica como también turística, debido a su importancia ecosistémica reconocida por la ciencia a nivel internacional. Sin embargo, en términos globales las plantaciones forestales se encuentran concentradas en la depresión intermedia de la región, y la Selva Valdiviana en los sectores costeros y cordilleranos, lo que nos entrega una pauta para un ordenamiento territorial estratégico. Los impactos de las plantaciones forestales para el turismo, se presentan principalmente en comunas como Valdivia y Rio Bueno, donde la tala rasa de las plantaciones perjudica la belleza paisajística del entorno, lo que hace disminuir su atracción turística. Por otra parte los impactos sociales de la silvicultura a nivel regional y nacional son preocupantes, considerando que la actividad forestal se concentra desde la Región del Maule hasta la Región de Los Lagos, regiones que cuentan con el Índice de Desarrollo Humano (IDH) más bajo a nivel nacional y con la mayor cantidad de pobres, afectando además la disminución de la calidad y cantidad de 
agua para riego y consumo humano.

El impacto social de la silvicultura es bastante preocupante, sobre todo si analizamos que la brecha y distribución de la producción económica del rubro se concentra por pocas y grandes empresas forestales. Dentro de los principales impactos de la industria, sin considerar los mencionados como impactos paisajísticos, cabe mencionar el desastre ecológico del Santuario de la Naturaleza Carlos Anwandter, causa del inicio de operaciones de la Celulosa Arauco en el año 2004, el impacto fue un crimen a la biodiversidad, lo que disminuyó su atractivo natural, entorpeciendo la protección y planificación sustentable del recurso a largo plazo.

\section{3.- Desarrollo del sector Turismo y el sector Acuícola}

La principal incompatibilidad de la acuicultura con el turismo, se refiere a los impactos ambientales de esta actividad productiva, causadas por el alimento, la huella ecológica, la instalación de los centros de cultivos, los desechos y el uso de químicos (Bushman, 2001), que contribuyen a la eutrofización de las aguas, a la disminución del oxigeno por consumo y por consecuencia impactos en las cadenas tróficas, escapes de especies exóticas e interacción con especies nativas etc. Cabe mencionar la preocupante situación regional y nacional respecto al tema del impacto ambiental de la acuicultura, el cual no ha sido abordado ni estudiado eficientemente como para identificar los impactos para su mitigación, sin embargo, estudios internacionales demuestran las amenazas ambientales que presenta este tipo de actividad productiva, por ejemplo según Buschman (2001), diversos estudios realizados en diferentes partes del mundo demuestran que la huella ecológica considerada para un centro de cultivo tiene una influencia medioambiental diez mil veces superior a la de su superficie.

Dentro de la producción acuícola regional, destaca la piscicultura basada en salmónidos, que según las estadísticas de SERNAPESCA (2008) corresponden en su totalidad a truchas arcoíris. El principal problema de la salmonicultura radica en el alimento y desechos, debido a que las especies salmonídeas solo asimilan una parte de los nutrientes, quedando gran parte en el fondo de los cuerpos de agua, generando con esto un aumento del N y P. Según Buschman (2001), en 1994 la producción de 84 mil toneladas de salmones y truchas a nivel nacional, equivale a los desechos fecales de la mitad de la población de Santiago, como también que los desechos del cultivo de salmónidos de las regiones de Los Lagos, Los Ríos y de Aysén es mayor que los desechos de las poblaciones humanas de estas regiones. Asimismo, el uso de agentes químicos, como antibióticos, fungicidas y compuestos parasitarios generan desechos en las aguas, esto ha causado, según estudios demostrados, el aumento de la resistencia de baterías inocuas y patógenas, lo que podría influenciar y modelar la evolución a la resistencia bacteriana de los antibióticos en Chile (Cabello, 2004). 


\section{4.- Desarrollo del sector Turismo y el sector Pesca industrial.}

La pesca industrial explota por desembarque un total de 32.309 toneladas de especies acuáticas, 31.309 toneladas corresponden a peces y 900 toneladas a moluscos. La pesca industrial regional cuenta con 17 embarcaciones, 10 se dedican a la pesca por arrastre y 11 a la pesca de cerco (SERNAPESCA, 2008).

El principal y más alarmante impacto ambiental de la pesca industrial corresponde a la pesca de arrastre, debido principalmente que la primera arrasa con el fondo marino sin discriminar tipo de especies, arrasando con la biodiversidad de las profundidades, impactando directamente a la cadena ecológica, se ha prohibido en países como Venezuela donde se ha tomado conciencia sobre sus impactos ambientales, asimismo, se debe soslayar que para los pescadores artesanales en Chile está prohibida la pesca de arrastre. Los impactos que esta actividad puede causar es incalculable, afectando no solamente a niveles eco sistémicos, sino también en ámbitos socio económicos como en la pesca artesanal. La pesca de cerco (red de cerco), extrae especies acuáticas de media profundidad (pelágicas), afectando a lobos marinos y ejemplares inmaduros que al ser descartados generan un mayor impacto. Los impactos ambientales se transforman fácilmente en impactos sociales, sobre todo considerando a la actividad pesquera como una actividad económica de suma importancia para las familias de la costa valdiviana, de las comunas de San José de la Mariquina, Valdivia, Corral y La Unión.

\section{5.- Desarrollo del sector Turismo y el sector Energético.}

La generación de energía en la Región de Los Ríos se basa en la actualidad en la biomasa, hidroelectricidad y termoelectricidad (funcionan 2 termoeléctricas actualmente). En cuanto a la hidroelectricidad, la región cuenta con dos centrales, Pullinque y Pilmaiquén. Ambas se denominan como hidroeléctricas de pasada, la primera con una capacidad instalada de 51,4 MW y la segunda de $39 \mathrm{MW}$ respectivamente. Fuera de este escenario actual, existen una variedad de proyectos energéticos que pretenden instalarse en la región, en su mayoría hidroelectricas, en 2009 solo dos de estos proyectos correspondían a termoeléctricas, como la Central Calle Calle en base a diesel con una potencia instalada de $20 \mathrm{MW}$ y la termoeléctrica de biomasa Central Paneles Paillaco. Diecisiete hidroeléctricas en el año 2009 pretendían instalarse en la región, 3 eran reconocidas como hidroeléctricas de embalse, mientras que 14 se denominaban como hidroeléctricas de pasada. Las hidroeléctricas de embalse correspondían a la Central Rucatayo que contempla la construcción de una presa de 42,5 $\mathrm{m}$ de altura que inundaría 46,41 há, con una potencia instalada de $60 \mathrm{MW}$. La Central San Pedro con una potencia instalada de $144 \mathrm{MW}$, la presa inundaría 284 há, de las que 132 há corresponden a bosque nativo (Selva Valdiviana). La Central Los Lagos con un muro de 36,2 mt de altura y con 
un embalse de 156,6 há, su potencia instalada corresponde a 52,9 MW.

Fuera de la dimensión de las repercusiones ambientales y sociales de las termoeléctricas en la región, las termoeléctricas actuales mas las proyectadas en el caso regional son un número minoritario y su impacto ambiental, turístico, social es mucho menor que el que se presenta por las centrales hidroeléctricas futuras en su conjunto. Actualmente el principal conflicto entre el sector energético y el turismo corresponde a la generación de energía hidroeléctrica. Debido principalmente a la construcción de centrales de embalse y a una gran concentración de pequeñas y grandes centrales de paso en la región. Dentro de estas centrales, las con mayores impactos sociales y ambientales corresponden a las centrales hidroeléctricas de embalse, sin embargo, también presentan grandes impactos las concentraciones de hidroelectricas de pasada en los territorios.

El principal impacto de las centrales hidroeléctricas de embalse, corresponde al territorio o área de inundación, las que en el ámbito regional varían desde 46 há hasta 256 há (centrales proyectadas en 2009). Al ser grandes extensiones de terreno, y por lo tanto casi imposible su limpieza total, quedan especies vegetales que se descomponen y ayudan a la eutrofización de las aguas, impactando a la biodiversidad biológica. Asimismo, en cuanto a la inundación de territorios, se pierde flora nativa y hábitats permitiendo la extinción o disminución de fauna nativa y endémica. Asi también, se identifican otros impactos sociales potenciales como el desplazamiento de comunidades indígenas por areas de inundación, este es uno de los principales impactos de la central hidroelectrica proyectada por Endesa - Enel en Lago Neltume, comuna de Panguipulli.

Los conflictos sociales de las hidroeléctricas de embalse y de pasada, son problemas con las comunidades locales, las que en muchos casos de la región no están de acuerdo con la ejecución de estos proyectos, asimismo no se han generado las instancias de participación social donde las comunidades vecinales expongan sus intereses. Dentro de estas voces de los residentes, también se encuentran comunidades indígenas las cuales se acogen al Convenio 169 de la OIT, firmado en 2008 por el Gobierno de Chile, para el resguardo de sus territorios ancestrales. Por ejemplo, el cementerio indígena de Reyehueico estaría dentro del área donde la Central Reyehueico pretende instalarse.

Otro gran problema social, ambiental y turístico de las hidroeléctricas tanto de embalse como de pasada, corresponde al proceso de construcción, principalmente en el aspecto ambiental por el constante tránsito de camiones que transportan materiales, y socialmente por la llegada de muchos trabajadores afuerinos a pequeños poblados o localidades, por lo que ejercería un gran impacto a las características culturales, de formas de vida y tradiciones. La Central San Pedro considera un periodo de construcción de 5 años, con un total de 500 a 900 trabajadores, y contempla solo 25 trabajadores para su funcionamiento (Centro de Ciencias Ambientales, 2007). Por lo que los impactos a las 
localidades en un plazo de 5 años, pueden disminuir la calidad de vida de los residentes locales e impulsar la caída de la demanda turística etc., para finalmente a mediano plazo generar muy pocos puestos de trabajo, que no necesariamente serán cubiertos por los residentes.

\section{4.- SINERGIAS ENTRE TURISMO Y OTROS SECTORES PRODUCTIVOS.}

El turismo de intereses especiales en el que espera basar su desarrollo turístico nuestro país, está influenciado directamente por las formas de vida, interacción con la naturaleza y desarrollo productivo del mundo rural. De esta forma la compatibilidad del turismo con el sector agropecuario, forestal y pesquero se torna trascendental. Las relaciones con otros sectores productivos se generan según el uso de los recursos naturales, por ejemplo, para realizar ecoturismo necesitamos bosques y senderos, para realizar turismo aventura necesitamos ríos, lagos, montañas etc. En este caso, la diversidad de actividades que se pueden realizar en un territorio, como la Región de Los Ríos, permite que existan sinergias con distintas formas de producción.

La mayoría de las sinergias se desarrollan por emprendimientos familiares, gran parte son lideradas por el agroturismo, sin embargo, existen alternativas productivas diferentes que también se desarrollan por residentes locales, como por ejemplo la pesca, la extracción de madera certificada, recolección de productos de recolección del bosque etc. En ese caso los puntos similares se refieren a las formas de producción familiares, que tienden a ampliar sus actividades con el turismo. Podemos encontrar ejemplos nacionales e internacionales sobre experiencias de sinergias entre pescadores artesanales y turismo, como también respecto al manejo de bosques. Asimismo sucede con la región de Los Ríos, donde existen varios ejemplos de sinergias productivas entre estos sectores. La mayoría de estas experiencias son de escala familiar, siendo el segmento objetivo para la puesta en valor de la sustentabilidad y las sinergias productivas.

\section{1.- Agroturismo como expresión de sinergias entre sector Turismo y sector Agropecuario.}

A nivel mundial se ha demostrado la compatibilidad del turismo con la actividad agrícola y ganadera: los emprendimientos turísticos han tomado esta forma de vida y trabajo, como una atracción que genera demanda. El turismo rural comprende diversas modalidades de turismo que no son excluyentes, sino más bien complementarias, como por ejemplo el turismo aventura, turismo cultural, ecoturismo y agroturismo (Martínez, 1997; in Constabel et al 2008). La oferta turística de las localidades o destinos, se nutren de diversos tipos de actividades. 
A nivel nacional por ejemplo, tenemos varias experiencias sinérgicas en el agroturismo. Se reconocen sinergias entre el agroturismo y la vitivinicultura, por ejemplo, en el Valle de Colchagua, donde las viñas han integrado al agroturismo como una oportunidad de negocio complementaria, mezclándose con tradiciones y costumbres criollas. Las empresas agroturísticas, en su mayoría pequeñas y medianas empresas, basan sus emprendimientos en servicios de alojamiento y alimentación, como también de actividades. Por ejemplo granjas educativas, agro campings, rucas, ferias, eventos campesinos, rutas agroturísticas, hospedajes familiares, quinchos, fogones y restaurantes campesinos.

En la comuna de Valdivia, existe un proyecto representativo de la atracción que genera el turismo rural tanto para turistas, como residentes y visitantes de lugares cercanos, es el caso de la feria costumbrista de Niebla que comenzó hace algunos años en temporada estival, y actualmente sigue operando en fines de semana o días festivos en lo largo del año. Esta feria ha podido reunir a microempresarios, en su mayoría gastronómicos, los que asociativamente han generado un producto tradicional, con gastronomía local y folclore.

Existen también muchos emprendimientos de turismo indígena en las comunas de Panguipulli y Lago Ranco, los que también clasifican en varias ocasiones como emprendimientos de agroturismo. En la costa de Valdivia también existen emprendimientos agroturísticos que presentan sinergias, por ejemplo, Península San Ramón e Isla Guacamayo. Punucapa es otro ejemplo de un destino agroturístico representativo de Valdivia, es un pueblo prehispánico, que en la actualidad vincula sus actividades productivas con el turismo, por ejemplo la producción de sidra, el uso de productos agrícolas y artesanales del lugar, etc. El agroturismo por ser una actividad rentable, de grandes oportunidades, se ha convertido en un objeto deseado por muchos territorios, que ven como de forma espontánea estos emprendimientos se desarrollan, generando motivaciones y demanda. Esa es la razón porque en la mayoría de los destinos turísticos del país se pueden encontrar iniciativas agroturísticas. En muchos destinos de gran atracción, el agroturismo está siendo protagonista en la diversificación de las actividades que puede realizar el turista de intereses especiales.

Según Constabel et al. (2008) en el libro "Agroturismo en Chile" menciona que los principios del agroturismo sustentable en relación con el medio rural son: preservación de los recursos y ecosistemas, armonía y crecimiento equilibrado entre los sistemas naturales y los silvoagropecuarios; incremento de la conciencia medioambiental de todos los agentes en el sector y el más amplio uso de energías amables con el medio ambiente.

De acuerdo a lo anterior, podemos visualizar que los principios del agroturismo sustentable, pueden ser similares a los del ecoturismo, turismo de pesca deportiva y 
recreativa si se desarrollan sosteniblemente, en este contexto podemos comprender que cualquier actividad de autoproducción, o producción local permite aumentar la calidad de vida de los residentes locales, la preservación del patrimonio cultural y natural, por lo que las sinergias productivas se deben desarrollar transversalmente de acuerdo a estos mismos criterios.

\section{2.- Ecoturismo y turismo histórico-cultural como expresión de sinergias entre sector Turismo y sector Silvícola.}

Hace algunos años la productividad del bosque se basaba en su explotación maderera, tal como sucedió en las comunas de Los Lagos y Panguipulli, sin embargo, actualmente es posible mediante el ecoturismo, conservar estos bosques y usarlos con fines educativos y de recreación que permitan producir renta familiar, pero al mismo tiempo conserven la naturaleza en el mediano y largo plazo. Existen varias áreas protegidas públicas y privadas en la región de Los Rios que conservan el bosque nativo o Selva Valdiviana, y que son utilizadas turísticamente, como senderos comunitarios, parques privados como la Reserva Costera Valdiviana, y areas protegidas del Estado como el Parque Nacional Alerce Costero, Parque Nacional Villarrica, Reserva Nacional Mocho Choshuenco, entre otras. El principal desafío de las areas protegidas del Estado, radica en la implementación de sistemas de co-administración con comunidades rurales y mapuche aledañas, que permitan su planificación participativa para su conservación a largo plazo.

La actividad forestal en la región de Los Ríos forma parte de la historia y del patrimonio tangible e intangible, sobre todo en lugares como Neltume, Choshuenco y Panguipulli. Siendo parte trascendental en la cultura y formas de vida tradicionales, en este contexto histórico, la potenciación del patrimonio ligado a esta temática permite vincularlo al turismo, creando instancias donde se pueda experimentar esta relación del bosque con su historia de explotación productiva, con la arquitectura y con los productos de recolección del bosque (hongos silvestres y frutos de estación).

\section{3.- Ecoturismo y Turismo Gastronómico como expresión de sinergias entre sector Turismo y sector Pesquero artesanal.}

La pesca se vincula con el turismo como una actividad de esparcimiento, deportiva y de recreación. Desde la visión productiva las sinergias se vinculan directamente con la pesca artesanal, que forma parte de las formas tradicionales de vida en la zona costera, de esta manera su aporte al patrimonio intangible de estas localidades es un aspecto a considerar, sobre todo en el comercio, representado en el caso regional en la Feria Fluvial de Valdivia y otros. La pesca artesanal se dirige al comercio local, donde sus mercados objetivos son principalmente restaurantes, ferias y mercados, nutriendo de insumos a la gastronomía local. Sin embargo, en la actualidad los pescadores artesanales no son actores 
activos en el turismo, es mas la pesca artesanal no se considera como un lineamiento para el desarrollo turístico de las comunas de San José de la Mariquina, Valdivia, Corral y la Unión.

A partir de esto podemos preguntarnos $i E s$ factible que la pesca artesanal tenga un uso turístico?, para encontrar una respuesta es necesario visualizar alguna experiencia, en ese caso un ejemplo representativo es lo que sucede en la Reserva Marina de Galápagos (Ecuador), allí se desarrolla actualmente la pesca artesanal vivencial, que consiste en que el pescador muestra al turista sus conocimientos, la cultura pesquera y la experiencia de vivir en armonía con la naturaleza. De esta forma no se extraen grandes volúmenes de productos marinos, lo que es una estrategia de conservación ambiental, con beneficios ecosocioeconómicos para la comunidad receptora y su territorio.

\section{5.- INCOMPATIBILIDADES PRODUCTIVAS.}

Otra situación se aprecia cuando los conflictos escalan a un nivel que hace imposible el desarrollo del turismo de intereses especiales junto a otros sectores productivos. En este escenario hablamos de incompatibilidad. Se identifican grandes conflictos que en el largo plazo pueden convertirse en incompatibilidades, por ejemplo la contaminación difusa, la generación hidroeléctrica, las plantaciones forestales, la salmonicultura y la pesca de arrastre. Si analizamos detenidamente los conflictos nos podemos percatar que son generados en su mayoría por la producción industrial más que la producción a pequeña escala o familiar.

\section{1.- Incompatibilidad entre Producción de Celulosa y Turismo de Intereses Especiales.}

La producción de celulosa aparece como incompatible con el TIE. El desastre natural en el Santuario Carlos Anwandter, producido en forma preponderante por el funcionamiento de la planta de celulosa en San José de la Mariquina, ha generado efectos que han causado enormes impactos en la biodiversidad, deteriorando el atractivo del Santuario y desvalorizando su uso turístico en el corto plazo.

\section{2.- Incompatibilidad entre Agricultura y Ganadería intensiva y Turismo de Intereses Especiales.}

La contaminación difusa según estudios internacionales se genera tanto en la ganadería como en la agricultura, causada por la depositación de altos niveles de nutrientes que mediante la lixiviación son arrastrados a los cuerpos hídricos, como los efluentes de los bovinos y el uso de pesticidas y fungicidas, lo que se agrava principalmente por la agroganadería extensiva e intensiva con fines industriales. La falta de información e 
investigación nacional respecto a esta materia, no nos permite cuantificar los impactos.

\section{3.- Incompatibilidad entre Producción Hidroeléctrica y Turismo de Intereses Especiales.}

La hidroelectricidad presenta un alto grado de conflicto debido principalmente al gran número de proyectos en carpeta, concentrados en un mismo territorio. Además muchos de estos proyectos se hacen clasificar como centrales hidroeléctricas de pasada, usando sin embargo embalses, por lo que no corresponden a la categoría mencionada. Las centrales hidroeléctricas que contemplan la construcción de embalses y superan la generación de $100 \mathrm{MW}$, presentan enormes impactos potenciales en los ecosistemas, $\mathrm{y}$ en las especies nativas y endémicas. La comuna de Panguipulli, por ejemplo, donde se concentra gran parte de los proyectos, puede verse muy afectada en el turismo termal y el ecoturismo, ya sea por los impactos ambientales, como por las consecuencias sociales.

Al igual que en otras partes del país, especialmente en la Patagonia con "Hidroaysén", que es el caso más representativo de los proyectos energéticos del país, las sociedades regionales se ven afectadas por requerimientos centralistas de índole nacional más que local, por lo que estos intereses no consideran los beneficios ecosocioeconómicos locales. Por una parte esta la necesidad energética y el interés nacional, y por otra empresas de otros lugares del mundo que no comparten territorio con los protagonistas locales y potenciales afectados, en busca de inversiones rentables. En este sentido, como menciona Napadensky (2007) acontece una pauperización de los recursos regionales a favor de objetivos nacionales, ya que muchas de las nuevas infraestructuras energéticas están localizadas en regiones del norte y sur del país, aunque el mayor consumo energético se encuentra en el área urbanizada de la zona central.

\section{4.- Incompatibilidad entre Producción Forestal y Turismo de Intereses Especiales.}

Las plantaciones forestales en su mayoría son de pino insigne y eucaliptos, reemplazan a las especies nativas, disminuyendo la Selva Valdiviana, desertificando los suelos, aumentando los niveles de N y P en los sistemas hídricos, como también perjudicando la belleza paisajística regional con la tala rasa de las plantaciones.

\section{5.- Incompatibilidad entre Salmonicultura y Turismo de Intereses Especiales.}

La salmonicultura es otro foco de conflicto que en el largo plazo puede convertirse en una incompatibilidad. El alimento de los salmones y sus respectivos desechos, como también los agentes químicos (antiparasitarios, antibióticos y fungicidas), generan depositación y erosión del fondo de los cuerpos hídricos, por ende contaminación de las aguas, disminución de la biodiversidad y evolución de la resistencia de bacterias 
patógenas, etc.

\section{6.- Incompatibilidad entre Pesca Industrial y Turismo de Intereses Especiales.}

La pesca de arrastre por otra parte, es una actividad tremendamente dañina para el fondo marino y sus especies animales y vegetales. Ha sido prohibida por algunos países y solamente está prohibida para la pesca artesanal en Chile, genera pérdidas irreparables para los ecosistemas del mar. Esta es una actividad que nutre de insumos a las plantas pesqueras.

\section{7.- Sinergias, conflictos e incompatibilidades.}

A continuación se presenta una figura explicativa del panorama general de las principales sinergias, conflictos e incompatibilidades productivas del TIE con otros sectores de la región.

\section{Figura 1.}
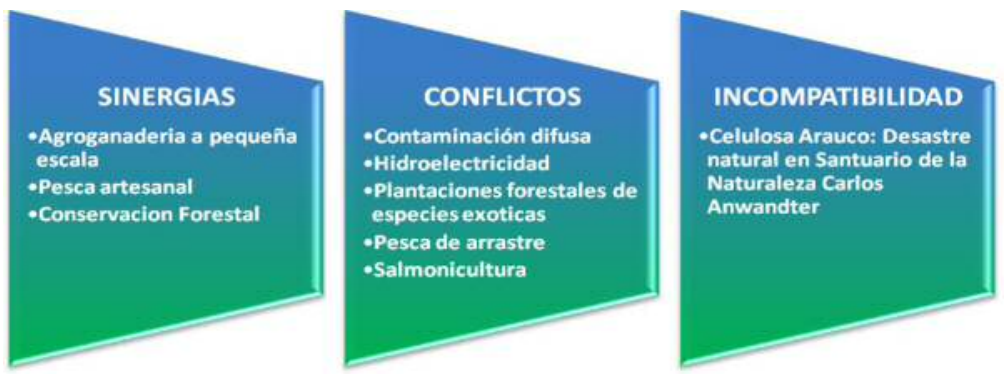

\section{6.- CONCLUSIONES.}

- Se concluye que las actividades productivas y proyectos existentes que se encuentran en conflicto y potencial incompatiblidad, dado sus impactos socioambientales, no se encuentran en un proceso de solución por el interés competitivo del uso del territorio, principalmente por no existir instancias reales de participación y validación social de actividades productivas industriales a gran escala en desmedro de los emprendimientos locales. Asimismo, la inexistencia de un ordenamiento territorial estratégico perjudica los débiles instrumentos legales que cuenta el turismo a nivel municipal, siendo de esta manera el turismo de intereses especiales una actividad incipiente con grandes riesgos de incompatibilidad productiva y proclive a declinar en el largo plazo, si no se generan 
políticas de desarrollo imbricadas a las gobernanzas locales, y que sean pertinentes a garantizar el desarrollo de esta actividad junto a los emprendimientos familiares existentes en las zonas rurales de la región y el sur del país.

- Las actividades productivas con mayor interacción con el TIE corresponden a los sectores agropecuario, forestal, acuícola, minero y energético. Los recursos naturales donde se produce esta interacción entre el TIE y otros sectores productivos son: ríos, lagos, mar, paisajes, bosques y volcanes etc.

- Podemos dilucidar que existen actividades productivas con mayor grado de sinergia y conflicto, es decir, algunas son más compatibles con el desarrollo turístico que otras.

- Algunos sectores productivos presentan sinergias con el TIE, por ejemplo, el agroturismo tiene una clara sinergia con la producción agropecuaria. Asimismo, la pesca artesanal y la conservación forestal con el turismo cultural, aquí es posible experimentar las formas de vida de las comunidades locales. En el caso regional, la agroganadería es bastante compatible con el TIE, debido a ser uno de los pilares de la producción local, generando sinergias en las actividades productivas de las familias rurales principalmente. De manera potencial también se identifican claras sinergias entre pesca artesanal y turismo, así lo dicen los ejemplos internacionales, y el constante esfuerzo de muchos territorios en fusionar estas actividades, que son parte de la cosmovisión de los residentes de la costa, siendo parte esencial del patrimonio de estas localidades. De la misma forma sucede con la conservación forestal en la región, se observan sinergias en áreas naturales protegidas públicas y privadas, que con el manejo sustentable del bosque han podido formar parte de los atractivos naturales para realizar ecoturismo en la Selva Valdiviana.

- Existen disputas de intereses entre los sectores productivos y el TIE que se han podido o aún se pueden solucionar, pudiendo convivir los diferentes sectores productivos en un mismo territorio. Por lo tanto, es plausible la convivencia de distintos sectores, siempre cuando se realicen esfuerzos de negociación y mediación para los cuales el sector turístico está disponible, pero otros sectores no parecen tan disponibles. Tal es el caso de la ganadería extensiva, la silvicultura, la generación energética a baja escala, la pesca industrial, etc. Por ejemplo, si se protegiera la belleza paisajística del entorno, sin tala rasa en áreas especificas, o si se dimensionara la contaminación difusa de la producción de la agroganadería extensiva y se establecieran normas para disminuirla, etc.

- Existen subsectores productivos cuya interacción con el TIE, es mayoritariamente conflictiva, y alcanza un alto grado de incompatibilidad, tal es el caso de la industria forestal, la producción de celulosa, la producción energética a gran escala, la industria ganadera a gran escala y la pesca industrial. 
- Para la superación paulatina de los conflictos productivos, es necesario avanzar inicialmente con las sinergias, siendo una estrategia que permite direccionar esfuerzos en virtud de disminuir los conflictos antes de que se conviertan en incompatibilidades. Para esto las familias rurales, con su producción local o a pequeña escala, son los principales socios estratégicos para fomentar las buenas prácticas productivas desde el plano local, para así fortalecer las bases del crecimiento productivo sustentable en los territorios.

$\mathrm{Si}$ bien, existen sinergias entre turismo y otras actividades productivas, es preeminente que el turismo, sobre todo el de intereses especiales, lidere el tema de las buenas prácticas productivas, para de esta forma, invitar a otros sectores a consolidarse en esta materia, generando mayores sinergias y disminuyendo los desagradables conflictos ambientales y sociales. Las prácticas productivas, que son las acciones para llevar a cabo las actividades productivas, deben transformarse en buenas prácticas productivas. Para ello es necesario fomentarlas a través de los encadenamientos productivos actuales y potenciales, generando encadenamientos de buenas prácticas productivas.

Los encadenamientos de buenas prácticas productivas, enfocados en unidades territoriales determinadas, pueden convertirse en una herramienta fundamental para la certificación, desde la producción a pequeña escala hasta la producción industrial. Sobre todo si se comienza a trabajar desde las acciones de producción sustentables actuales para arrastrar las acciones perjudiciales al ecosistema, tratando de disminuir las brechas de manera paulatina, finalizando en destinos planificados sosteniblemente. Para estas metas es fundamentalmente necesario el liderazgo de municipios y gobiernos regionales.

- Por último, es necesario señalar que existen importantes impactos generados, pero no suficientemente dimensionados ni aún estimados, con efectos a mediano y largo plazo y por ende potenciales fuentes de conflictos e incompatibilidades entre TIE y otros sectores productivos.

\section{BIBLIOGRAFÍA}

Alfaro, M \& Salazar, F. (2005). Ganadería y Contaminación Difusa, Implicancias para el Sur de Chile. Agricultura Técnica. 2005, vol..65, n.3, pp. 330-340.

Austermühle, S. (2005). "Protejamos al mar profundo. Pesca de Arrastre". Deep Sea Conservation Coalition. (DSCC). Perú.

Bannister, J. (2007) Proyectos hidroeléctricos en la "Región de las Represas". Bosque Nativo. n.42, pp.8-10.

Buschmann, A. (2001) Impacto ambiental de la acuicultura. El estado de la investigación en Chile y el mundo. Depto de Acuicultura, Universidad de Los Lagos. Chile.

Cabello, F. (2004). Antibióticos y acuicultura en Chile: consecuencias para la salud humana y animal. Revista médica de Chile, vol.132, n.8, pp. 1001-1006. 
Ceballos - Lascurraín, H. (1998) Ecoturismo, Naturaleza y Desarrollo Sostenible. Diana, México.

Centro de Ciencias Ambientales (2007) Estudio de Impacto Ambiental Central Hidroeléctrica San Pedro. Universidad de Concepción, Chile.

Constabel, S., Oyarzun, E., Szmulewicz P. et. al. (2008) Agroturismo en Chile. Caracterización y Perspectivas. Fundación para la Innovación Agraria. Universidad Austral de Chile. Santiago de Chile.

Comisión Europea. Comunicación al Consejo Europeo y al Parlamento Europeo: Una política Energética para Europa. \{SEC(2007) 12\}, Bruselas, COM(2007). 10 de Enero 2007.

Dirección General de Aguas. Listado de Solicitudes de Proyectos Hidroeléctricos Ingresados a la DGA - Santiago, 14 de Agosto de 2009.

Donoso, P \& Otero, L. Hacia una definición de país forestal: ¿Dónde se sitúa Chile? Bosque (Valdivia). 2005, vol.26, n.3, pp. 5-18.

Donoso, C. et. Al. Comité Editor. El sector forestal chileno: necesidad de un equilibrio. Bosque Nativo. 2007.n. 42,pp. 2-3.

EC, European Community (1991) Council concerning the protection of water against pollution caused by nitrates from agricultural sources. Official Journal of the European Community (91/676/EEC), Lesgislation 1375/1-375/8, European Community.

Empresa Eléctrica Pilmaiquén S.A. (2008). Proyecto Central Hidroeléctrica Osorno. Región de Los Ríos, Chile.

Farías, A et. Al. (2004). Análisis del avance hasta la fecha en la definición de las áreas prioritarias para la conservación de la biodiversidad en la Región de los Lagos. Documento $N^{o}$ 8. Serie de Publicaciones WWF- Chile. Programa Ecoregión Valdiviana.

Gestión Ambiental Consultores (2009). Descripción de Proyecto SEIA Central Hidroeléctrica Maqueo. Capitulo 2. Región de Los Ríos, Chile.

Napadensky, A. (2007). Chile: Paisajes rurales y producción energética ¿Pauperización o transformación sinérgica? Revista de Desarrollo Rural y Cooperativismo Agrario, (10): 195-204.

Pain, B. (1994). Reducing Emissions from Land Associated with Rumiant Production. In: Proceedings of the 15th. tr Mabbetje, L. y Frame, J. (Eds.). General Meeting of the European Grassland Federation. Wageningen (Netherland). pp.2909-301.

Pliscoff, P et. al. (2005). Análisis de Paisaje de Conservación para la Cordillera de la Costa de la Región de los Lagos. WWF - Valdivia, Chile.

Registro Nacional de Acuicultura (2008). Subsecretaría de Pesca, Gobierno de Chile.

Rivas, H. Los Impactos Ambientales en áreas Turísticas Rurales y propuestas para la Sustentabilidad. Gestión turística. (Valdivia), 1998, no.3, p.47-79. ISSN 07186428. 
Salazar F. (2005) Prácticas de Manejo, Leyes y Normas para la utilización de purines y efluentes de lecherías. Instituto de INIA, Boletín Técnico Remehue $\mathrm{N}^{\circ} 244$

Servicio Agricola y Ganadero (2004). "Medidas de mitigación de impactos ambientales en fauna silvestre". Servicio Agrícola Ganadero - Chile.

Servicio Nacional de Pesca y Acuicultura. Anuario 2008. Servicio Nacional de Pesca, Gobierno de Chile.

Subsecretaría de Pesca (2006). Informe Ambiental de la Acuicultura. Departamento de acuicultura., Gobierno de Chile.

World Wild Fund (2009). Documento de Posición. Pesca de Arrastre de Fondo. WWFValdivia, Chile. 